\title{
Process parameters analysis of direct laser sintering and post treatment of porcelain components using Taguchi's method
}

\author{
Xiaoyong Tian ${ }^{\mathrm{a}, \mathrm{b}, *}$, Jens Günster ${ }^{\mathrm{b}}$, Jörg Melcher ${ }^{\mathrm{c}}$, Dichen $\mathrm{Li}^{\mathrm{a}}$, Jürgen G. Heinrich ${ }^{\mathrm{b}}$ \\ a State Key Laboratory of Mechanical Manufacture System Engineering, Xi'an Jiaotong University, Xi'an 710049, China \\ ${ }^{\mathrm{b}}$ Department for Engineering Ceramics, Clausthal University of Technology, Clausthal-Zellerfeld 38678, Germany \\ ${ }^{\mathrm{c}}$ Institute of Composite Structures and Adaptive Systems, German Aerospace Center, Braunschweig 38108, Germany
}

Received 23 September 2008; received in revised form 24 November 2008; accepted 2 December 2008

Available online 14 January 2009

\begin{abstract}
The effects of laser sintering parameters (laser power, scan speed and hatching space) and post sintering process (heating rate, sintering temperature and holding time) on the physical and mechanical properties of porcelain components have been investigated. The study has been carried out using the Taguchi's method for the experimental design. In the laser sintering process, lower laser energy density and higher hatching space will increase the final mechanical properties of the porcelain components. A stress relief principle has been put forward to explain the different influence of the factors. The appropriate laser sintering parameters are attained in this paper: laser power $50 \mathrm{~W}$; scan speed $85 \mathrm{~mm} / \mathrm{s}$; and hatching space $0.6 \mathrm{~mm}$. Sintering temperature has been determined to be the most important factor in the post sintering process. Appropriate sintering temperature for the laser sintered porcelain bodies is in the range of $1425-1475^{\circ} \mathrm{C}$ regarding the mechanical properties of the porcelain components. The maximum bending strength, $34.0 \pm 4.9 \mathrm{MPa}$, is reached.
\end{abstract}

(C) 2008 Elsevier Ltd. All rights reserved.

Keywords: Direct laser sintering; Mechanical properties; Porcelain; Mullite; Structural application

\section{Introduction}

Ceramics have many outstanding physical and chemical properties and attract lots of researchers' attentions to find new industry applications for this kind of material such as components resistant to the high temperature, ${ }^{1}$ piezoelectric sensor and actuators. ${ }^{2,3}$ However, ceramic components with complex structures cannot be shaped by the conventional formation process such as casting, forging and machining. Industrial applications of ceramic materials are largely restricted by the lack of the netshaping capability for the components with complex structures.

When rapid prototyping came into being at the end of last century, the general purpose was just to make prototypes in order to reduce the time of product development by shortening the period between design and test. But now functional components, specially using metal or ceramic materials, are manufactured by the

\footnotetext{
* Corresponding author at: Department for Engineering Ceramics, Clausthal University of Technology, Zehntnerstrasse 2a, Clausthal-Zellerfeld 38678, Germany.

E-mail address: leoxyt@mail.xjtu.edu.cn (X. Tian).
}

rapid prototyping process. ${ }^{4-8}$ Rapid prototyping provides several processes to realize the net shaping of the ceramic functional components such as stereolithography of the ceramic slurry, selective laser sintering of ceramic powder and 3D printing. Selective laser sintering (SLS) is a more promising process than other methods because the ceramic bodies fabricated by this method have a lower shrinkage and higher density after post sintering.

The fabrication process described in present paper is a kind of SLS which uses the layer-wise slurry deposition (LSD) instead of ceramic powder. ${ }^{9,10}$ High density green layers are attained after drying because of the deposition of slurries. Consequently, sintering is more activated and the densities of the green bodies as well as the post sintered ceramic bodies are higher than the traditional SLS processes.

Porcelain slurry has been used in the present work to investigate the laser sintering and post sintering processes. The laser sintering process using layer-wise slurry deposition has been investigated only by Günster et al. ${ }^{9}$ and Gahler et al. ${ }^{10}$ The slurry used by Gahler was alumina and silica for the dental ceramic components and porcelain slurry by Günster. Dental porcelain 
slurry was also used by Shaw as the raw material in the multimaterial extrusion and laser densification process. ${ }^{11,12}$ But the relationships between laser sintering process and properties of the ceramic components were not mentioned in their studies. For a ceramic part in industrial applications, the mechanical properties are very important. So, the relationships between the process parameters and the mechanical properties have been carefully investigated in the present work.

There are already abundant literatures about the properties of porcelain components fabricated by the conventional processes. The influence of firing conditions, filler grain size and quartz content etc. on the microstructures, phase compositions and bending strength has been widely researched. ${ }^{13-17}$ But the post sintering process has been carefully reinvestigated again in this paper because of the different formation processes of the green bodies, uniaxial pressure in the conventional process and laser sintering in the present work. The distinct microstructures and properties of the green bodies will cause different post sintering process and final mechanical properties.

The main intention of the present work is to investigate the laser sintering parameters and the post sintering process, and then to find out the relationships between all the factors in the processes and microstructures and mechanical properties of the final ceramic components.

\section{Experimental procedure}

\subsection{Experimental design}

After the ceramic samples are fabricated by LSD and laser sintering, the samples are post sintered to eliminate the pores in the green bodies and then improve their mechanical strength. In LSD and laser sintering process, four parameters should be investigated, laser power, scanning speed, hatching space and layer depth. But in present work the depth of each layer is constant, $0.1 \mathrm{~mm}$, for all the experiments. Three levels for other three parameters are applied as shown in Table 1 . The values of each level have been chosen according to the previous experiment results. In post sintering process, there are three main parameters needed to be considered, heating rate, sintering temperature and holding time. Three levels for each parameter are applied as shown in Table 2 within the ranges usually used in the industrial practice for the porcelain productions.

There are two basic statistical methods to design an experimental investigation, ${ }^{18}$ namely full factorial and fractional factorial experiment design. When the numbers of factors and levels for each factor are large, full factorial experimental

Table 1

Values of each level for the factors in laser sintering process.

\begin{tabular}{|c|c|c|c|}
\hline Factors & Level 1 & Level 2 & Level 3 \\
\hline Laser power (W) & 40 & 50 & 60 \\
\hline Scan speed $(\mathrm{mm} / \mathrm{s})$ & 85 & 100 & 150 \\
\hline Hatching space $(\mathrm{mm})^{\mathrm{a}}$ & 0.3 & 0.45 & 0.6 \\
\hline
\end{tabular}

a Central distance between two parallel laser scanning lines.
Table 2

Values of each level for the factors in post sintering process.

\begin{tabular}{lccr}
\hline Factors & Level 1 & Level 2 & Level 3 \\
\hline Heating rate $\left({ }^{\circ} \mathrm{C} / \mathrm{min}\right)$ & 10 & 15 & 20 \\
Sintering temperature $\left({ }^{\circ} \mathrm{C}\right)$ & 1225 & 1275 & 1325 \\
Holding time $(\mathrm{min})$ & 10 & 60 & 120 \\
\hline
\end{tabular}

Table 3

Experimental scheme for the laser sintering process, L9 $\left(3^{4}\right)$ orthogonal array.

\begin{tabular}{llllc}
\hline Run & Factors & & $e^{\mathrm{a}}\left(\mathrm{J} / \mathrm{cm}^{2}\right)$ \\
\cline { 2 - 4 } & $\begin{array}{l}\text { Laser } \\
\text { power }(\mathrm{W})\end{array}$ & $\begin{array}{l}\text { Scan speed } \\
(\mathrm{mm} / \mathrm{s})\end{array}$ & $\begin{array}{l}\text { Hatching } \\
\text { space }(\mathrm{mm})\end{array}$ & \\
\hline R1 & 40 & 85 & 0.3 & 78.43 \\
R2 & 40 & 100 & 0.45 & 66.67 \\
R3 & 40 & 150 & 0.6 & 44.44 \\
R4 & 50 & 85 & 0.45 & 98.04 \\
R5 & 50 & 100 & 0.6 & 83.33 \\
R6 & 50 & 150 & 0.3 & 55.56 \\
R7 & 60 & 85 & 0.6 & 117.65 \\
R8 & 60 & 100 & 0.3 & 100 \\
R9 & 60 & 150 & 0.45 & 66.67 \\
\hline
\end{tabular}

${ }^{\mathrm{a}}$ Laser energy density which can be calculated by Eq. (1).

design is impractical. To reduce the experiment times, fractional factorial experimental design is always adopted by many researchers.

Taguchi's fractional factorial design method is one of the most widely used design methods. ${ }^{19,20}$ In Taguchi's method, the experiments are limited to a special subset of the full factorial experimental array. In present work, a four by nine experimental matrix, according to Taguchi's method, is used. This array, referred in the literatures ${ }^{21,22}$ as the L9 $\left(3^{4}\right)$ orthogonal array, is present in Tables 3 and 4 . There are just three factors selected in the laser sintering and post sintering processes, so there should be a blank factor column in the L9 $\left(3^{4}\right)$ array. In Tables 3 and 4 , the blank columns have been deleted. The laser energy density (e) is not the experiment factor and can be calculated by Eq. (1).

Table 4

Experimental scheme for the post sintering process, L9 $\left(3^{4}\right)$ orthogonal array.

\begin{tabular}{lllc}
\hline Run & Factors & \\
\cline { 2 - 4 } & $\begin{array}{l}\text { Heating rate } \\
\left({ }^{\circ} \mathrm{C} / \mathrm{min}\right)\end{array}$ & $\begin{array}{l}\text { Sintering } \\
\text { temperature }\left({ }^{\circ} \mathrm{C}\right)\end{array}$ & $\begin{array}{l}\text { Holding time } \\
(\mathrm{min})\end{array}$ \\
\hline R1 & 10 & 1225 & 10 \\
R2 & 10 & 1275 & 60 \\
R3 & 10 & 1325 & 120 \\
R4 & 15 & 1225 & 60 \\
R5 & 15 & 1275 & 120 \\
R6 & 15 & 1325 & 10 \\
R7 & 20 & 1225 & 10 \\
R8 & 20 & 1275 & 60 \\
R9 & 20 & 1325 & \\
\hline
\end{tabular}




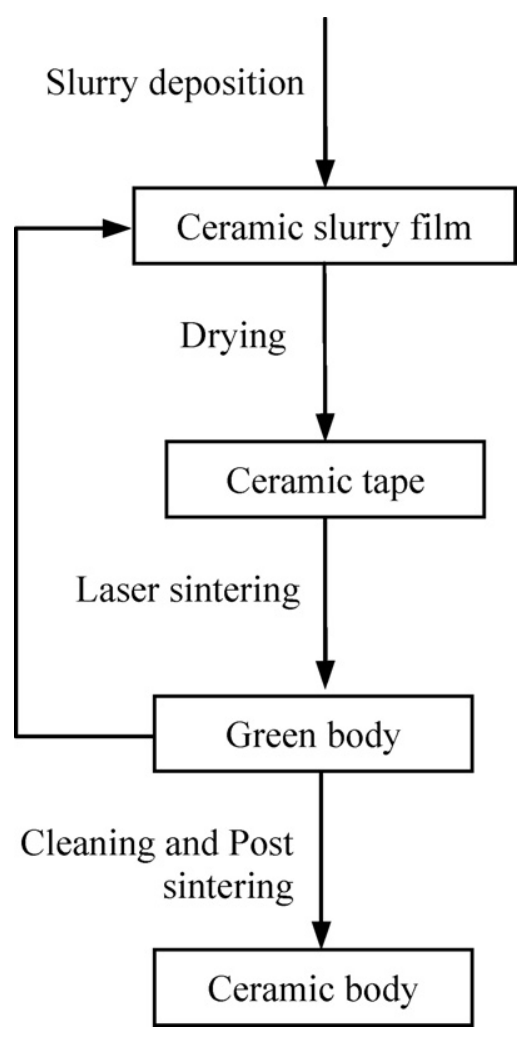

Fig. 1. Fabrication process of porcelain components using LSD and laser sintering.

\subsection{Materials and sample preparation}

The porcelain slurry (PM905) used in present work was provided by Imerys (Tirschenreuth, Germany). The rheological properties of the slurry were characterized with a coaxial cylinder shear rate-controlled viscosimeter (Haake VT550, Karlsruhe, Germany). The viscosity of the porcelain slurry was $1.483 \mathrm{Pas}$ with the shear rate $100 \mathrm{~s}^{-1}$ at room temperature. It has been proved in the following experiments that the slurry is appropriate for the layer-wise deposition. The solid composition of the porcelain slurry was analyzed by using XRD.

The fabrication process of the ceramic components is shown in Fig. 1. Similar to the tape-casting process, the slurry was deposited via a doctor blade on a preheated (up to $200^{\circ} \mathrm{C}$ ) tile. The slurry was supplied by a dispenser pump (Dispenser 3NDP8, Netzsch, Germany). A worktable with a higher kinematic resolution, $6.25 \mu \mathrm{m} / \mathrm{step}$ for vertical motion and $12.5 \mu \mathrm{m}$ per step for horizontal motion, was used to achieve the slurry deposition. A laser system with a Rofin Sinar $\mathrm{SC} 10 \mathrm{CO}_{2}$ laser tube (100 W) (Hamburg, Germany) and a galvano-scanner (Hurryscan, Scanlab AG, Germany) had been introduced into the experiments.

\subsection{Sample characterization}

TG/DT analysis for the green and laser sintered bodies were carried out with a Netzsch STA 409 apparatus (Germany). Density and porosity of the post sintered ceramic specimens were measured using Archimedes's technique in water. Bend- ing strength of 10 specimens for each experiment group was determined using a 4-point bending method. The specimens for the bending strength test were fabricated into a standard size $(45 \mathrm{~mm} \times 4 \mathrm{~mm} \times 3 \mathrm{~mm})$ without polishing. Crystal phases identification was performed by X-ray diffraction (Siemens diffractmeter D 5000, Siemens AG, Germany). The microstructures of the post sintered ceramic bodies were studies by means of optical microscopy (KP-50 color digital, Hitachi, Japan) and scanning electron microscopy (SEM, CamScan CS4 Cambridge, UK), both on polished and etched surfaces of the specimens.

\subsection{Statistical analysis}

Data analysis and interpretation were performed by using ANOVA (ANalysis of VAriance) method. ${ }^{22}$ The significance tests of each factor were carried out. The insignificant factors were ignored in the following experiments by using middle or preset values.

\section{Results and discussion}

\subsection{Laser sintering process}

Before the investigation of the laser sintering process, the ranges of each experiment parameters were pre-selected. Thereafter, the influence of these parameters on the properties of the porcelain samples was investigated.

\subsubsection{Pre-selection of the laser sintering parameters}

The laser energy density (LaserED) applied on the surface of the dried slurry can be defined ${ }^{23}$ as

LaserED $\left(\mathrm{J} / \mathrm{cm}^{2}\right)=\frac{P}{D \times V}$

where $P$ is the laser power, $D$ is the diameter of the laser beam $(0.6 \mathrm{~mm}$ in present work) and $V$ is the laser scanning speed.

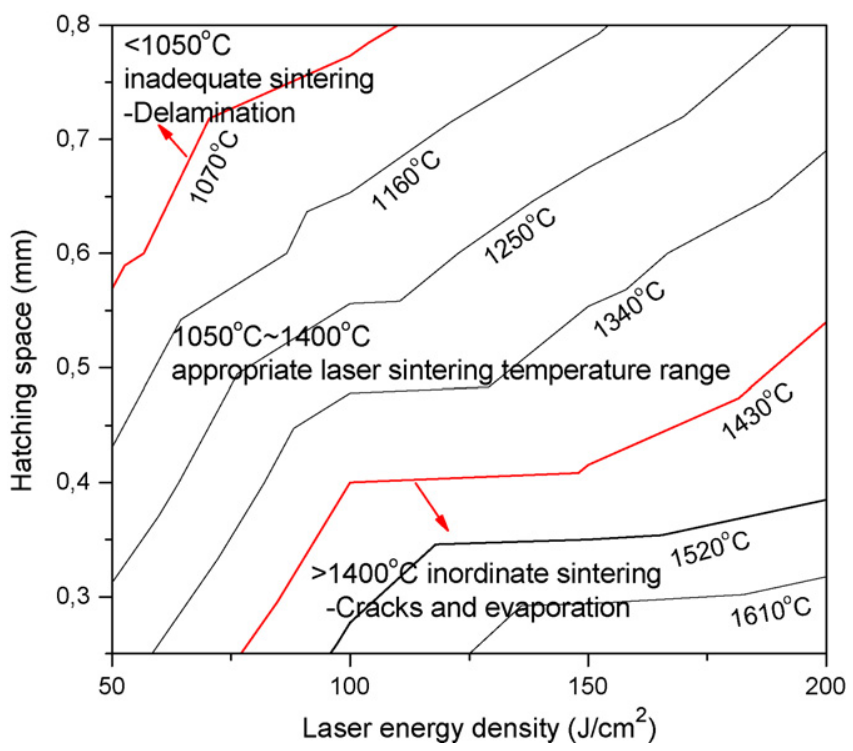

Fig. 2. Influence of laser energy density and hatching space on the temperature of the laser sintering zone. 
The values of $P$ and $V$ are adjustable in the laser sintering process. According to Eq. (1), the energy density increases with an increase in laser power and a decrease in laser scanning speed.

A pyrometer was installed in the laser sintering equipment to simultaneously measure the temperature of the laser sintering zone. The specimens with different sintering temperature were investigated according to the delamination of two adjacent layers or cracks on the surface. An isothermal map of sintering temperature on hatching space and laser energy is plotted in Fig. 2. It shows that higher laser energy density and lower hatching space produce higher sintering temperature.

In the inadequate sintering region of Fig. $2\left(T<1050{ }^{\circ} \mathrm{C}\right)$, the green bodies delaminated just because of the lower sintering temperature. In the inordinate sintering region of Fig. 2 the cracks (Fig. 3b) appear in the surface of the sintered bodies due to the higher temperature $\left(T>1400^{\circ} \mathrm{C}\right)$. On the contrary, in the appropriate laser sintering temperature range $\left(1050-1400^{\circ} \mathrm{C}\right.$ in Fig. 2), the laser sintered surface is homogenous and there are no cracks in it (Fig. 3a).

The experiment parameters were chosen according to the results in Fig. 2. Laser energy density is determined by the laser power $(P)$ and scanning speed $(V)$. The appropriate values of the
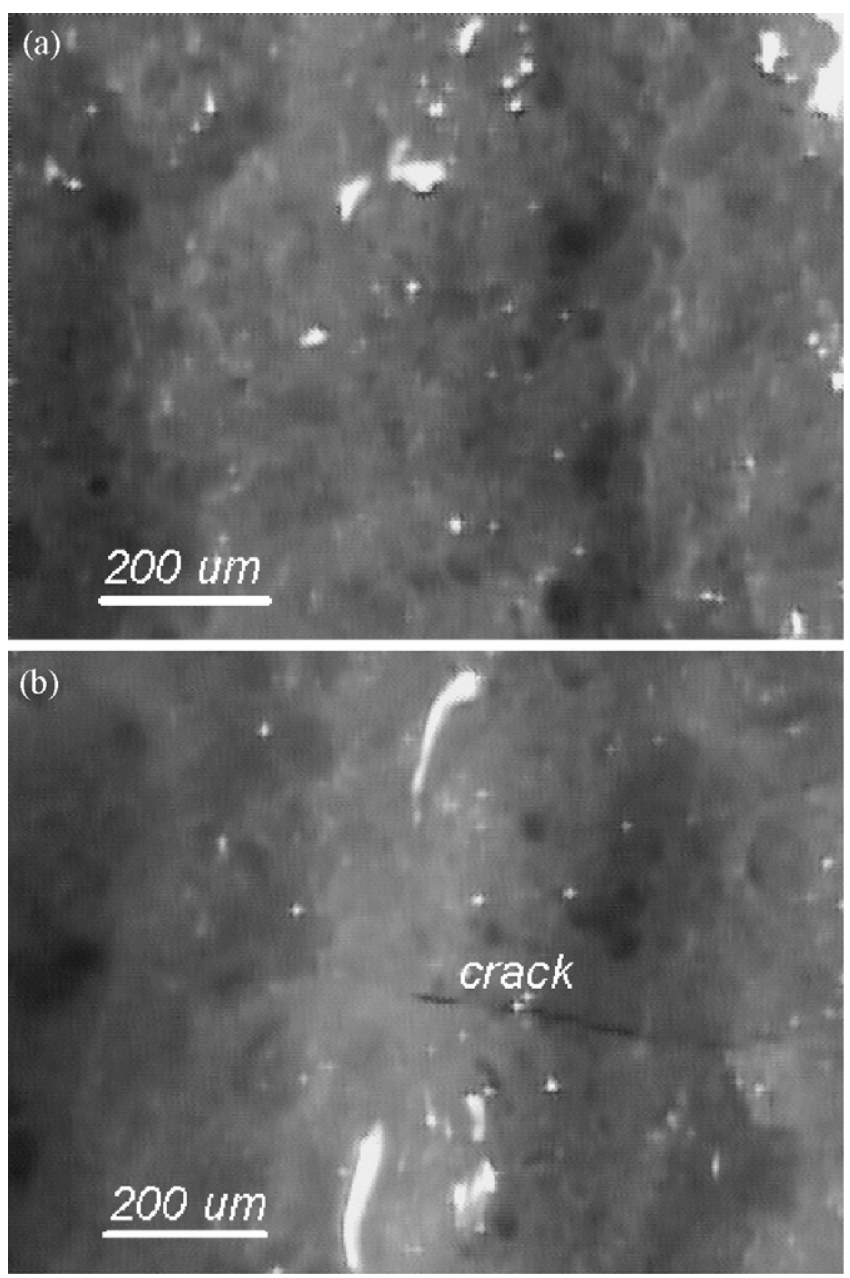

Fig. 3. Optical micrographs of laser sintered surface treated with different laser energy density (laser scanning parameters: laser power $45 \mathrm{~W}$, hatching space $0.6 \mathrm{~mm}$, scan speed: (a) $60 \mathrm{~mm} / \mathrm{s}, 125 \mathrm{~J} / \mathrm{cm}^{2}$ and (b) $30 \mathrm{~mm} / \mathrm{s}, 250 \mathrm{~J} / \mathrm{cm}^{2}$ ).

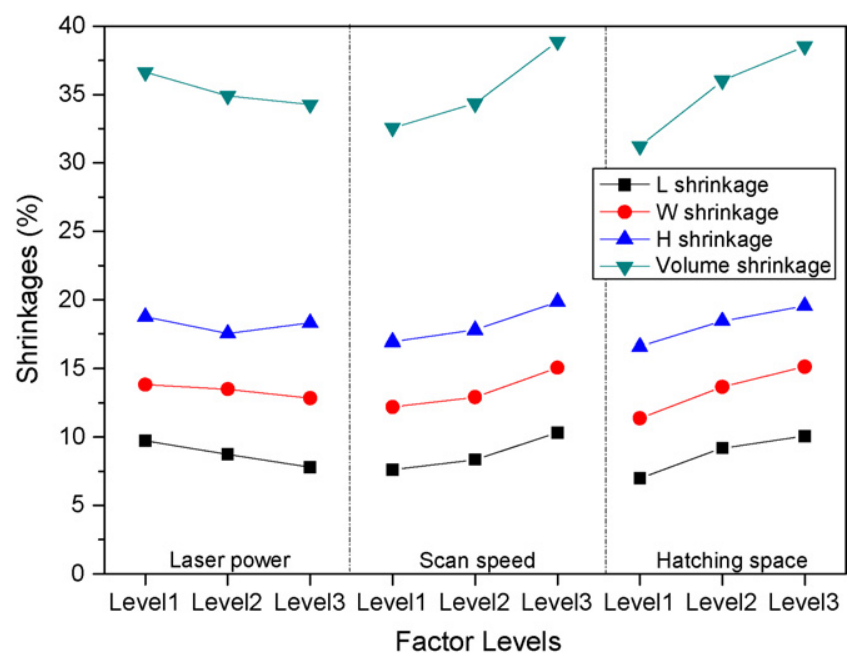

Fig. 4. Average effect of each laser sintering factor upon the shrinkage of the ceramic samples during the post sintering process.

hatching space, laser power and scan speed are listed in Table 3. The relationships between these experiment parameters and the properties of the post sintered porcelain bodies will be discussed in the following sections.
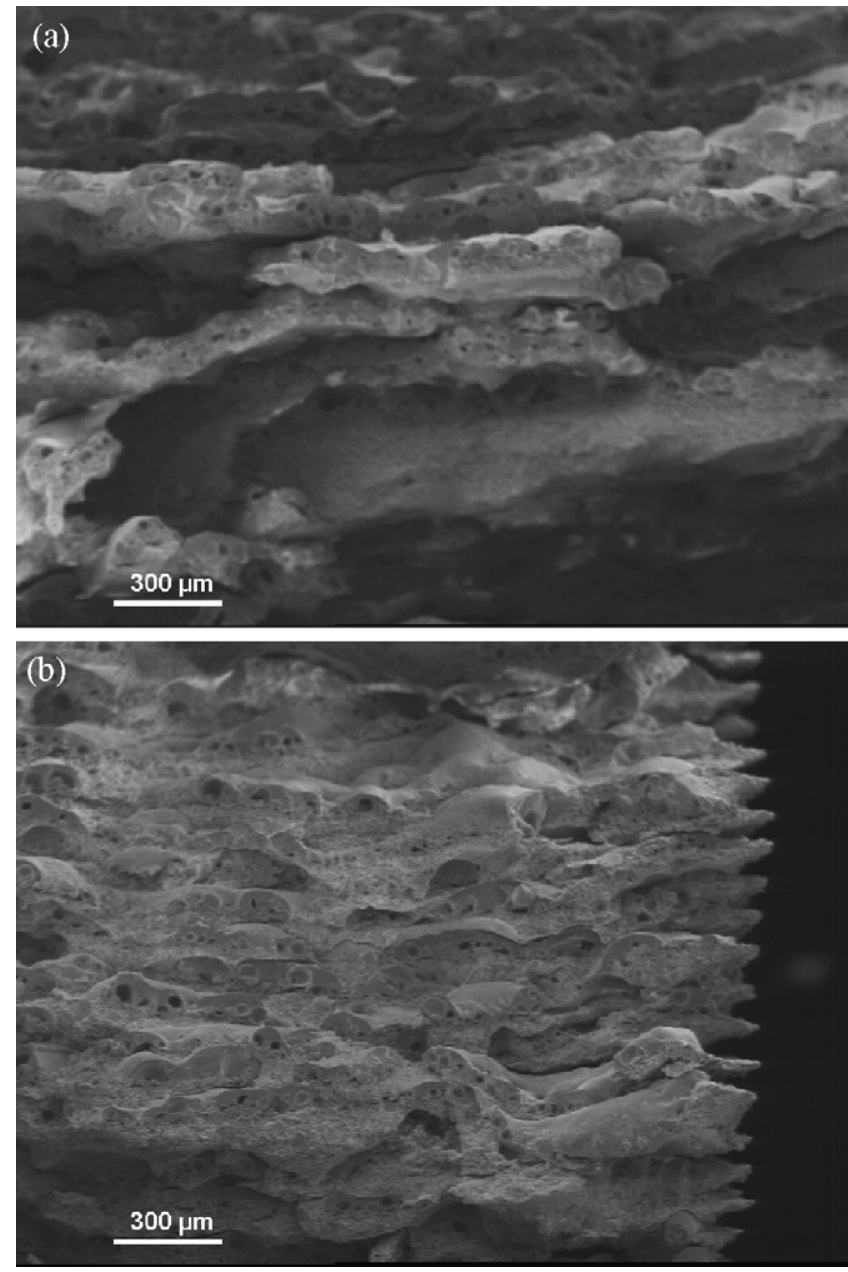

Fig. 5. Microstructures of fresh fracture surfaces in the samples after laser sintering without post treatment (a, R3; b, R5) (SEM). 


\subsubsection{Dimension retention}

The linear and volume shrinkage, $\Delta L / L$ and $\Delta V / V$, between laser sintered green bodies and post sintered porcelain parts, have been measured and the statistical results are shown in Fig. 4. There is a noticeable increasing trend of shrinkage with the increase of scan speed or hatching space and decreasing one with increase of laser power. In no case the average effect of the volume shrinkage exceed $40 \%$. But just for one single experiment result, the volume shrinkage of Run3 in Table 4 reached a maximum value, $43 \%$, and the maximum linear shrinkage were $12.26 \%, 17.09 \%$, and $22.37 \%$, in length, width and height, respectively.

The value of linear shrinkage was close to the results of Maity and Sarkar's, max $20 \%,{ }^{15}$ but much higher than the results of Martin-marquez's, max $5.0 \%{ }^{24}$ Contrast with the laser sintering process in the present work, the porcelain samples were uniaxially pressed in these references.

From Eq. (1), the laser energy density is in direct proportion to the laser power and inverse proportion to the scan speed. In Fig. 4 lower laser power as well as higher scan speed increases the shrinkage of the porcelain bodies when being post sintered.
It means that in the post sintering process lower laser energy density will produce the larger shrinkage of the porcelain bodies. From Fig. 2, with lower laser energy density and larger hatching space, the temperature in the laser sintering zone is lower. So the conclusion can be drawn that lower laser sintering temperature will cause larger shrinkage and higher densification during the post sintering process.

\subsubsection{Microstructures}

In order to understand how the different changing trends of the shrinkage appeared, it is useful to investigate the change of microstructures before (Fig. 5) and after being post sintered (Fig. 6).

The surface morphology of post sintered specimens was carefully investigated on fresh fracture surfaces (Fig. 6) by SEM. In Fig. 6, obvious delaminations are found in R1 and R8. The common feature of these two groups is the same value of hatching space, $0.3 \mathrm{~mm}$. The laser energy densities of $\mathrm{R} 1$ and $\mathrm{R} 8$ are 78.43 and $100 \mathrm{~J} / \mathrm{cm}^{2}$, respectively. In Fig. 2, these two groups of experiments fall in the inordinate sintering region $\left(T>1400^{\circ} \mathrm{C}\right)$. The delaminations between two adjacent layers are due to the
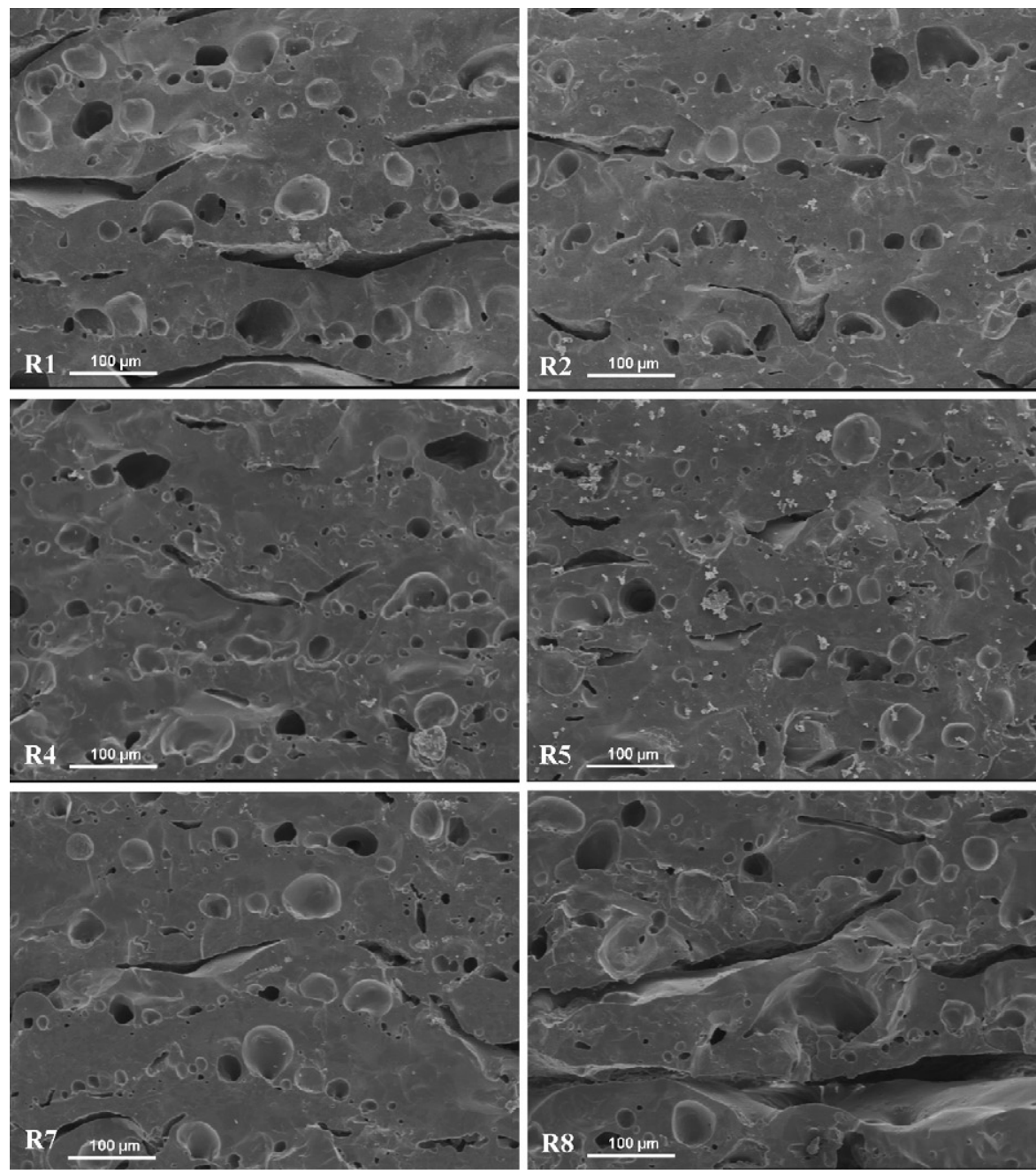
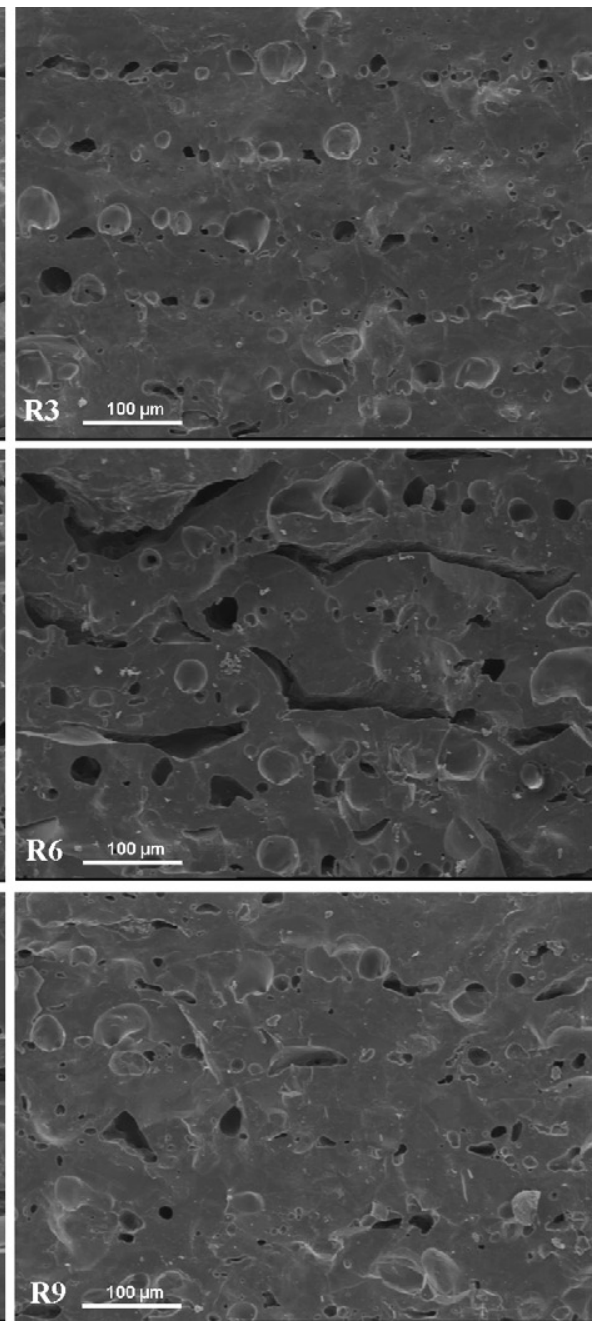

Fig. 6. SEM micrographs of microstructures in fresh fracture surfaces of the post sintered $\left(1425^{\circ} \mathrm{C}\right)$ samples with different laser energy density and hatching space: (R1) $78.43 \mathrm{~J} / \mathrm{cm}^{2}, 0.3 \mathrm{~mm}$; (R2) $66.67 \mathrm{~J} / \mathrm{cm}^{2}, 0.45 \mathrm{~mm}$; (R3) $44.44 \mathrm{~J} / \mathrm{cm}^{2}, 0.6 \mathrm{~mm}$; (R4) $98.04 \mathrm{~J} / \mathrm{cm}^{2}, 0.45 \mathrm{~mm}$; (R5) $83.33 \mathrm{~J} / \mathrm{cm}^{2}, 0.6 \mathrm{~mm}$; (R6) $55.56 \mathrm{~J} / \mathrm{cm}^{2}, 0.3 \mathrm{~mm}$; (R7) $117.65 \mathrm{~J} / \mathrm{cm}^{2}, 0.6 \mathrm{~mm}$; (R8) $100.0 \mathrm{~J} / \mathrm{cm}^{2}, 0.3 \mathrm{~mm}$; (R9) $66.67 \mathrm{~J} / \mathrm{cm}^{2}, 0.45 \mathrm{~mm}$. 


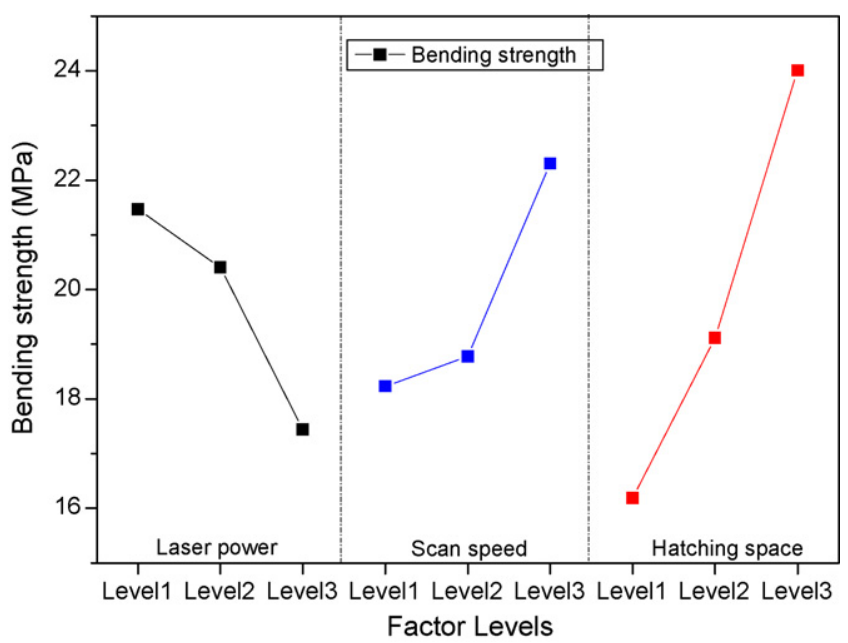

Fig. 7. Average effect of each laser sintering factor upon the bending strength of the ceramic samples.

residual thermal stress produced by the laser inordinate sintering. The residual stress cannot be freely released during the post sintering process, and then the cumulation of the stress finally causes the delamination between adjacent layers and cracks in the sintering surface.

On the contrary, the most densified microstructure in Fig. 6 is $\mathrm{R} 3$ which has a hatching space of $0.6 \mathrm{~mm}$ and laser energy density of $44.44 \mathrm{~J} / \mathrm{cm}^{2}$ which belongs to the inadequate sintering region in Fig. 2. The samples in this group actually delaminated after the laser sintering process and it is consistent with the description of Fig. 2. The microstructure of the laser sintered body in R3 is shown in Fig. 5a. Because of the inadequate laser sintering, there are lots of unsintered regions between two adjacent layers and the combination of the two adjacent layers is loose. When the samples are post sintered, these remained loose regions freely release the residual stress and then tightly combine the two layers with each other producing a most densified microstructure (Fig. 6R3). These can be considered as a stress relief principle which influences the microstructure and the mechanical properties of the ceramic specimens after being post sintered.

In contrast to the loose combination of the samples in group R3 (Fig. 5a), the microstructure of R5 is more compact (Fig. 5b), but after post sintering samples in group R3 have a more homogeneous and dense microstructure than the samples in group $\mathrm{R} 5$. This is also consistent with the stress release function of the loose unsintered regions between two adjacent layers.

\subsubsection{Bulk density and bending strength}

Bulk density and bending strength were measured to judge the importance of laser sintering parameters, hatching space, scan speed and laser power.

The average effect of laser sintering parameters upon the bending strength is shown in Fig. 7. The change trend of bending strength is similar with the shrinkage in Fig. 4. Larger hatching space and lower laser energy density (lower laser power and higher scan speed) increase the bending strength of the ceramic specimens. The change pattern of the bending strength is consis-

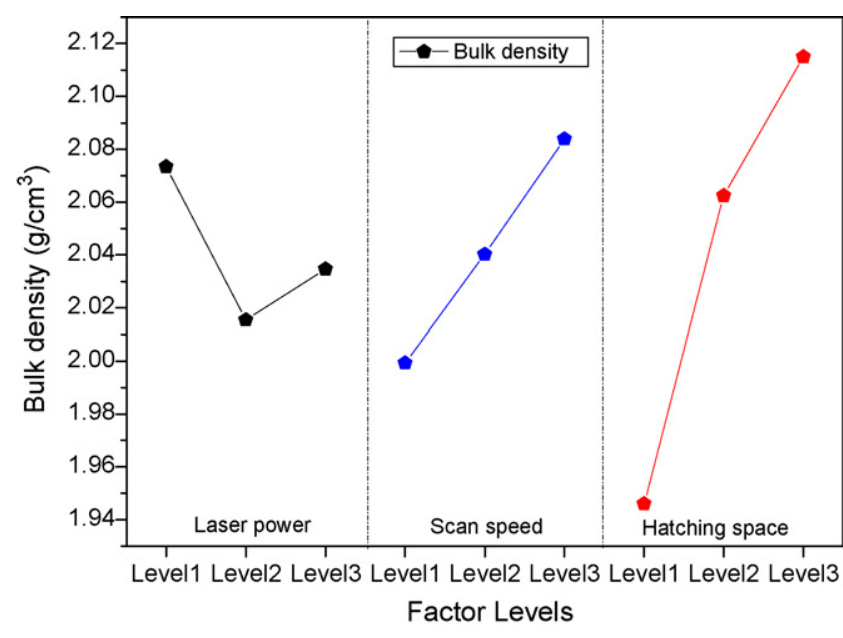

Fig. 8. Average effect of each laser sintering factor upon the bulk density of the ceramic samples.

tent with the microstructures and the stress relief principle. The bulk density is shown in Fig. 8. With increasing bulk density the bending strength increases.

The maximum value of the bending strength is $29.3 \pm$ 1.0 MPa in group $\mathrm{R} 3$ which has a most densified microstructure (Fig. 6R3). But because the green bodies in group R3 delaminated after the laser sintering process and had a lower green strength, the laser sintering parameters in this group cannot be adopted in the following experiments.

By the contrary to R3, samples in R5 have relative densified microstructure in the green bodies (Fig. 5b) and relative high bending strength $(23.8 \pm 1.6 \mathrm{MPa}$, higher than $\mathrm{R} 9$ $19.5 \pm 2.5 \mathrm{MPa}$, Fig. 9) after post sintering, so the laser sintering parameters in the group R5, power $50 \mathrm{~W}$, scan speed $85 \mathrm{~mm} / \mathrm{s}$ and hatching space $0.6 \mathrm{~mm}$, are more appropriate than others.

The bending strength was directly measured using the post sintered samples without surface polishing. So the value of the bending strength still can be improved by surface treatment.

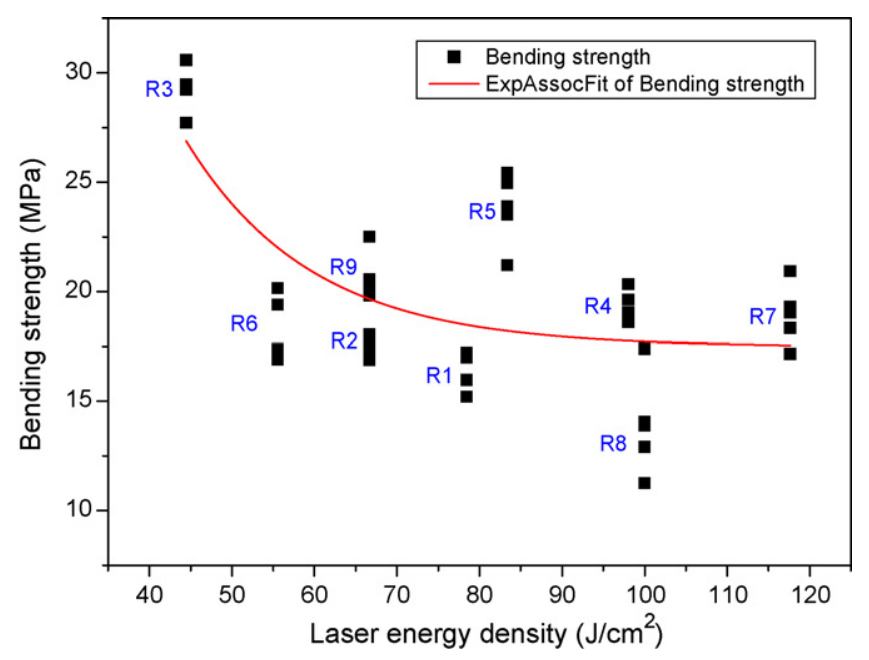

Fig. 9. Relation between laser energy density and the bending strength of the ceramic samples. 


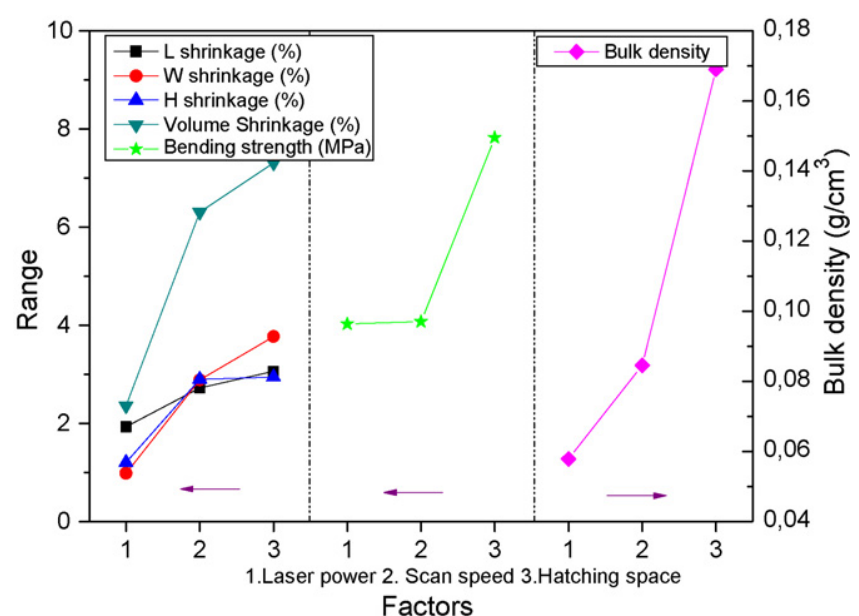

Fig. 10. Range analysis for the effect of three factors on the shrinkage and bending strength of the ceramic samples.

Because bending strength is greatly influenced by hatching space, the relation between laser energy density and bending strength is not obvious, shown in Fig. 9. The maximum bending strength is still achieved when the laser energy density got a minimum value $\left(44.44 \mathrm{~J} / \mathrm{cm}^{2}, \mathrm{R} 3\right)$.

\subsubsection{Range analysis}

The influence degree of each laser sintering parameter on the properties of ceramic samples is plotted in Fig. 10. Hatching space has the strongest influence on the shrinkage and bending strength among these three factors. Scan speed has a bigger influence on the shrinkage than laser power, but lower than hatching space. In case of bending strength, the laser power and scan speed are less significant than the hatching space.

Considering the properties of the green bodies, the laser energy density should be chosen as low as possible with lower laser power and higher scan speed under the condition that the green bodies will not delaminate and have some green strength enough for the handling. The hatching space should be as high as possible, but lower than the diameter of the laser beam.

\subsection{Post sintering process}

The specimens used in the post sintering process were produced using these parameters, laser power $45 \mathrm{~W}$, scan speed $50 \mathrm{~mm} / \mathrm{s}$, hatching space $0.6 \mathrm{~mm}$ and layer depth $0.1 \mathrm{~mm}$.

\subsubsection{Significance evaluation for each process parameter}

The results of experiments designed in Tables 2 and 4 were analyzed using ANOVA method. Shrinkage, porosity and density are considered as the important properties of the porcelain bodies. The average effect for the influence of the factors on the shrinkage, porosity and density are plotted in Figs. 11-13, respectively.

Heating rate has little influence on the properties of the ceramic samples. The porosity has a small but obvious increase with the raise of the heating rate (Fig. 12). At a higher heating rate, the gases entrapped in the porcelain bodies cannot

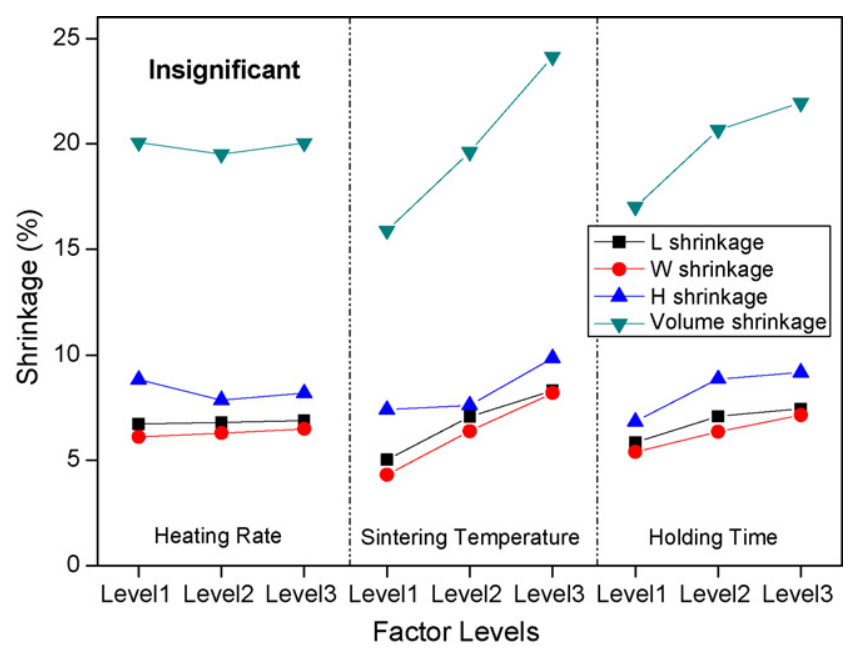

Fig. 11. Average effect of each factor upon the shrinkage of the ceramic samples.

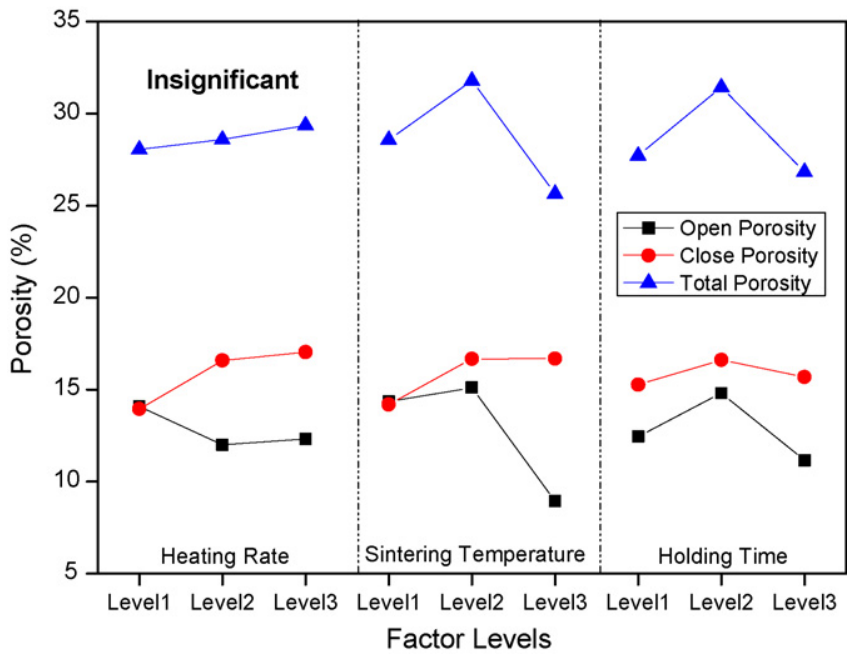

Fig. 12. Average effect of each factor upon the porosity of the ceramic samples.

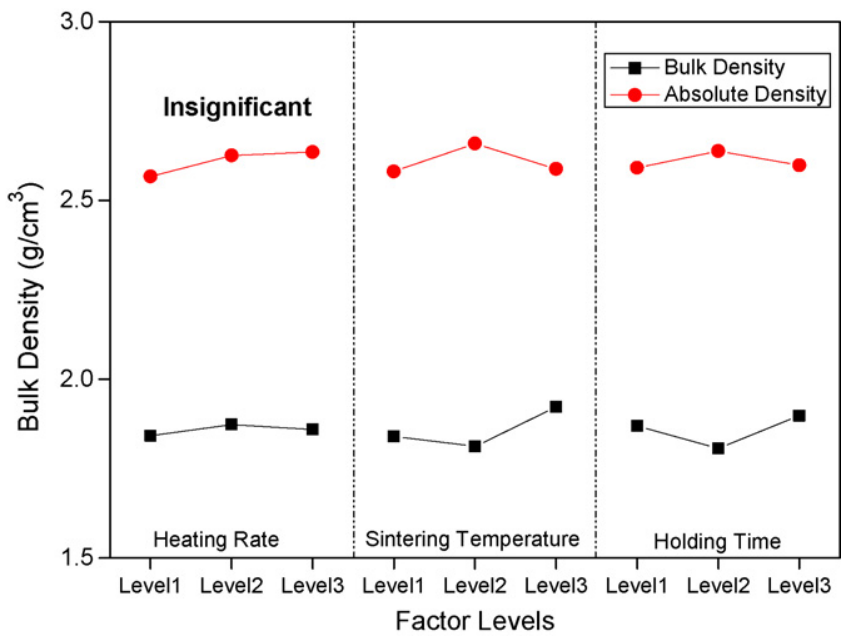

Fig. 13. Average effect of each factor on the density of the ceramic samples. 
be expelled from the inside as soon as possible. This probably causes the increase of the porosity. The influence of heating rate on the shrinkage and density is more insignificant.

Sintering temperature has large influence on the properties of the ceramic samples. Porcelain is a complicated triaxial system which has been studied by many researchers. ${ }^{13-17}$ In the present work, the initial composition is composed of relatively large quartz and feldspar grains in a fine-grained clay (kaoline) matrix (XRD results in Fig. 19 green body). The changes that occur in the structure of triaxial porcelain during firing depend to a great extent on the particular composition and conditions of firing. During firing the feldspar grains melt about $1140^{\circ} \mathrm{C}$. Around $1250^{\circ} \mathrm{C}$ feldspar grains which are smaller than about $10 \mu \mathrm{m}$ have disappeared by reaction with the surrounding clay. Fine mullite needles appear at about $1000^{\circ} \mathrm{C}$. With further increases of temperature mullite crystals continue to grow. ${ }^{27}$ Accompanying the transformation of the phases, the shrinkage increases with the rise of the sintering temperature, and a corresponding rise of the bulk density and decrease of the open porosity value. Optimum densification was achieved when the open porosity reached a minimum value. ${ }^{15}$

The results here show a little difference with the literatures which studied the sintering process of porcelain. The open porosity slightly rises and then decreases with the increase of the sintering temperature (Fig. 12b), instead of the direct decrease with the temperature just like the results in the literatures. ${ }^{14,15,24}$ The same situation happens to the bulk density (Fig. 13).

The primary reason for this distinction is the significant difference in the fabrication process between the present work and the literatures. In the literatures ${ }^{14-16}$ the samples were prepared by uniaxial pressure process, but in present work, the samples were prepared by the layer-wise slurry deposition and laser sintering. Different processes cause different microstructures and properties. In the laser sintering process, there are lots of pores between two single layers (Fig. 5). The gases entrapped between two layers will bloat and then split the adjacent layers at the lower temperature, causing the porosity increasing (Fig. 12) and the bulk density decreasing (Fig. 13) from 1225 to $1275^{\circ} \mathrm{C}$.

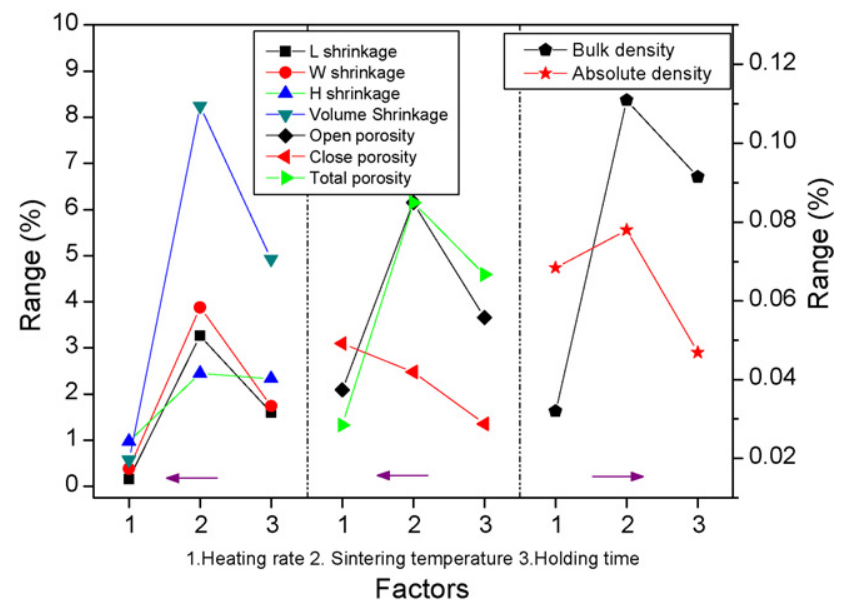

Fig. 14. Range analysis for the effect of three factors on the properties of the ceramic samples.

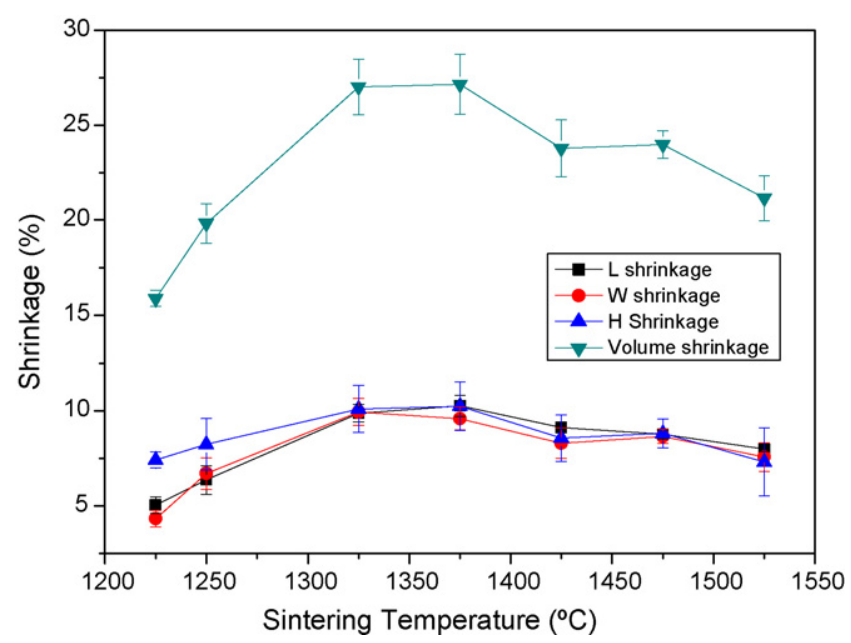

Fig. 15. Effect of sintering temperature on the shrinkage.

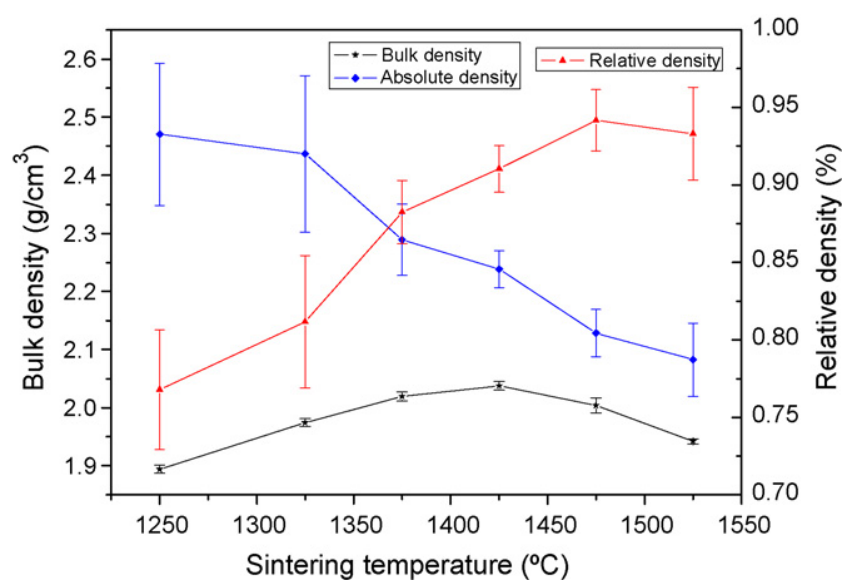

Fig. 16. Effect of sintering temperature on the density.

With the further rise of temperature, the glass phase appears and the cracks are diminished by the amalgamation of glass phase. And then, the porosity decreases and the bulk density increases. Whereas the linear shrinkage of the porcelain samples are not influenced by the cracks between the adjacent layers, the shrink-

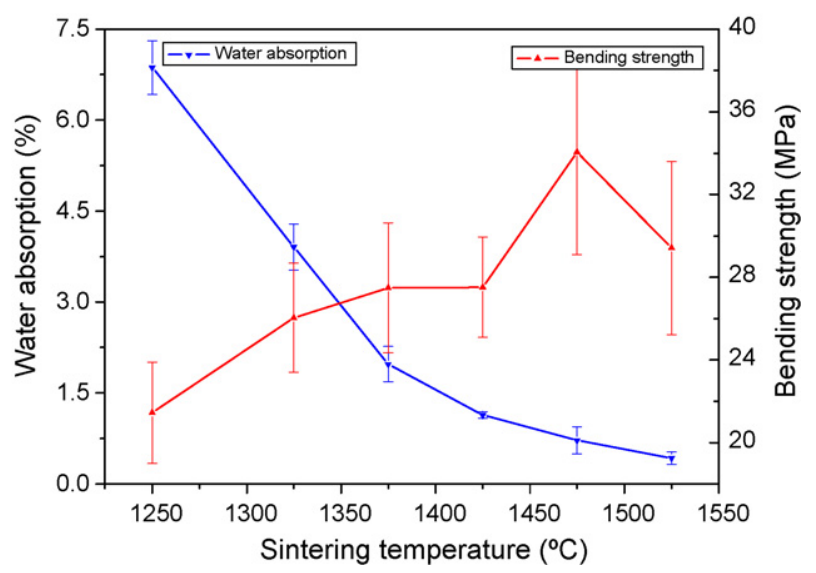

Fig. 17. Effect of sintering temperature on the water absorption and bending strength. 
age changes with sintering temperature just like the descriptions of the conventional porcelain ceramic in the literatures. ${ }^{14-17}$

Holding time has an analogous but small influence on the properties of porcelain bodies in contrast to the sintering temperature. The general equilibrium conditions for the porcelain system do not change at temperature above about $1200^{\circ} \mathrm{C}$ so that long holding time at this temperature give results that are very similar to the shorter times at higher temperature. ${ }^{27}$ The volume shrinkage just increases $1.2 \%$ when the holding time changes from 60 to $120 \mathrm{~min}$. The same value for the sintering temperature is $4.5 \%$ (Fig. 11). It means that the influence of holding time on the shrinkage slightly decreases when the holding time is up to $120 \mathrm{~min}$.

The results of the range analysis are shown in Fig. 14. The range can obviously reflect the significance of each factor. Heating rate holds the minimal value among the three factors. Heating rate will be ignored and the middle value $15^{\circ} \mathrm{C} / \mathrm{min}$ will be adopted as an invariant in the following experiments. The range of holding time is larger than heating rate's but smaller than sintering temperature's. The maximal value of holding time $120 \mathrm{~min}$ will be used in the following sintering process.

\subsubsection{Selection of the sintering temperature}

As discussed previously, sintering temperature has a pronounced effect on the properties of the ceramic samples. Under the normal firing conditions equilibrium is only achieved at temperatures above $1400^{\circ} \mathrm{C}$, and the structure consists of a mixture of siliceous liquid and mullite. In all cases the liquid at the firing temperature cools to form a glass so that the resulting phases present at room temperature are normally glass, mullite, and quartz. ${ }^{27}$ The relationship between sintering temperature and properties should be further investigated to find an appro-
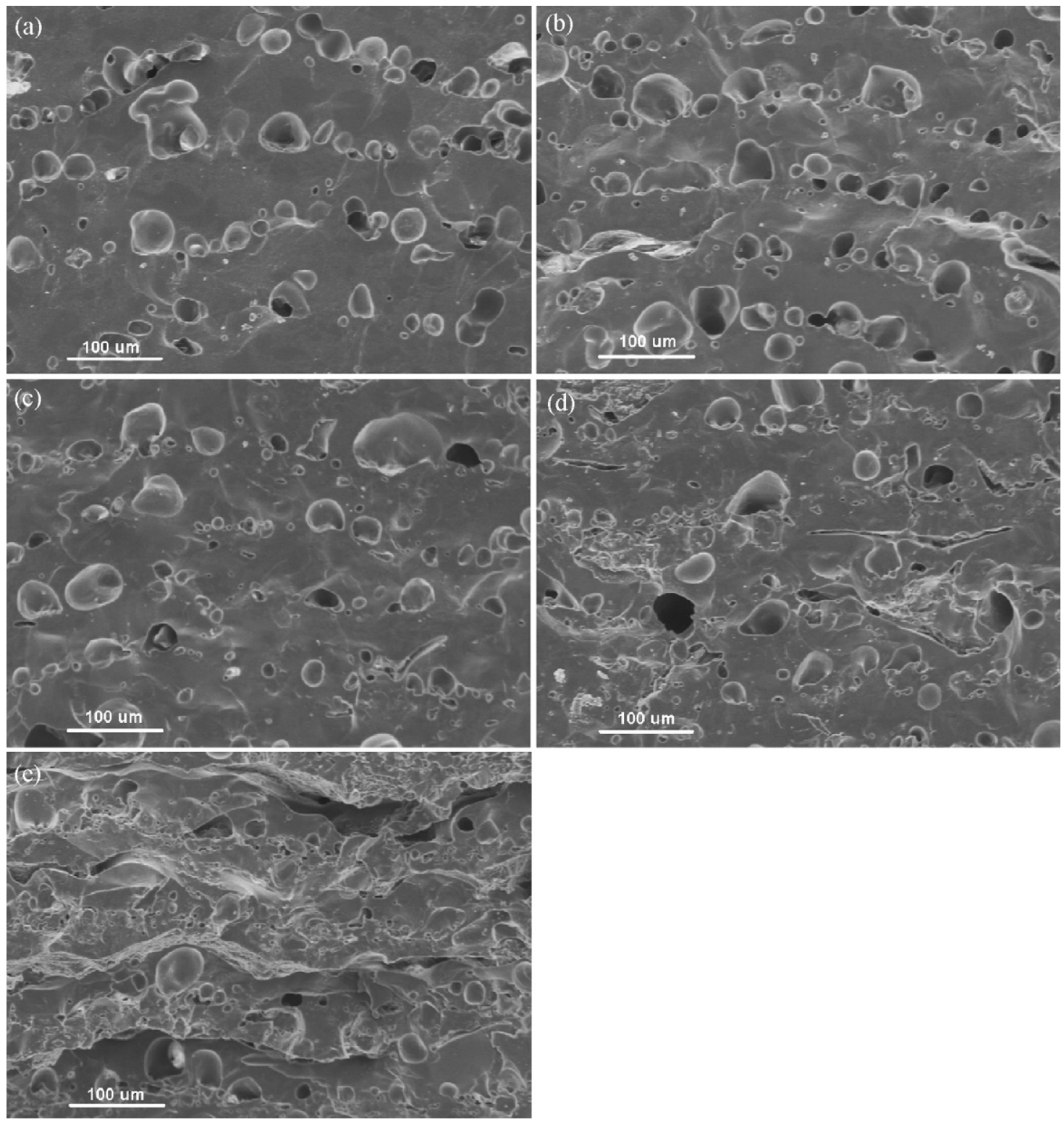

Fig. 18. SEM micrographs of the ceramic samples microstructures in different sintering temperature: (a) $1525^{\circ} \mathrm{C}$, (b) $1475^{\circ} \mathrm{C}$, (c) $1425^{\circ} \mathrm{C}$, (d) $1375^{\circ} \mathrm{C}$, and (e) $1325^{\circ} \mathrm{C}$. 
priate value by raising the sintering temperature to $1525^{\circ} \mathrm{C}$. Six batches of porcelain bodies were fired between 1250 and $1525^{\circ} \mathrm{C}$. The linear shrinkage, volume shrinkage, bulk density, relative density, water absorption and bending strength of the porcelain bodies were measured to characterize the densification behaviors. Results are shown in Figs. 15-17. All the properties basically show the similar trend which is typical for conventional porcelain parts except that the curves of bending strength and density are shifted for about $100^{\circ} \mathrm{C}$ to a higher temperature.

Fig. 15 clearly displays differential changes in linear shrinkage and volume shrinkage through the firing temperature. The shrinkage increases to a maximum value at $1325-1375^{\circ} \mathrm{C}$ and then decreases like the general behaviors of all conventional porcelain bodies. ${ }^{15,16,24}$ In Fig. 16 the bulk density reaches the maximum at $1425^{\circ} \mathrm{C}$ and relative density achieves the maximum at $1475^{\circ} \mathrm{C}$. There is a temperature shift of about $100^{\circ} \mathrm{C}$ between the maximum shrinkage and density. This is different compared with the conventional porcelain firing behaviors in which the shrinkages reached a maximum value at the exactly same temperature with the maximum density. ${ }^{15}$

Every single layer in laser sintering porcelain bodies is densified at $1325-1375^{\circ} \mathrm{C}$, but there are still interstices between two layers, as shown in Fig. 18e. The shrinkage decreases with increasing firing temperature to $1425^{\circ} \mathrm{C}$. The decrease of the shrinkage from 1325 to $1425^{\circ} \mathrm{C}$ is probably due to forced expulsion of entrapped gases, resulting in blister and bloating in the single layer. The pores in the single layer expand with the increasing temperature (Fig. 18). The interstices completely disappear when the sintering temperature increases to $1425^{\circ} \mathrm{C}$ (Fig. 18c). At the same temperature, the bulk density achieves its maximum. Disappearance of the interstices between adjacent layers causes the increase of the bulk density even though the pores in the single layer expand. But, from macroscopic perspective, the decrease of shrinkage conflicts with the increase of bulk density from 1325 to $1425^{\circ} \mathrm{C}$. This should be carefully studied again in the future work.

The bulk density reaches its maximum value at $1425^{\circ} \mathrm{C}$. The relative density reaches a maximum value just behind the bulk density about $50^{\circ} \mathrm{C}$ due to the decrease of the absolute density, as shown in Fig. 16. The maximum bending strength, $34 \pm 4.9 \mathrm{MPa}$, is achieved when the relative density reaches a maximum value at $1475^{\circ} \mathrm{C}$. Optimum densification is achieved when the water absorption, which is directly related to the open porosity, reaches a minimum value tending to be nearly zero. Firing above densification range results in a drastic fall of the mechanical properties (Fig. 17) due to the expulsion of the entrapped gases, resulting in blister and bloating. From Figs. 16 and 17, it can be concluded that laser sintered porcelain bodies' appropriate post sintering temperature is in the range of $1425-1475^{\circ} \mathrm{C}$.

Fig. 19 shows the X-ray diffractograms of the porcelain bodies, green, laser sintered and post sintered bodies with different sintering temperature in the $1250-1525^{\circ} \mathrm{C}$ interval. Quartz, kaolinite, potassium feldspar and illite phases were detected in the green bodies (Fig. 19f).

The changes taking place during post sintering occur at a rate depending on time, temperature, and particle size. The slowest

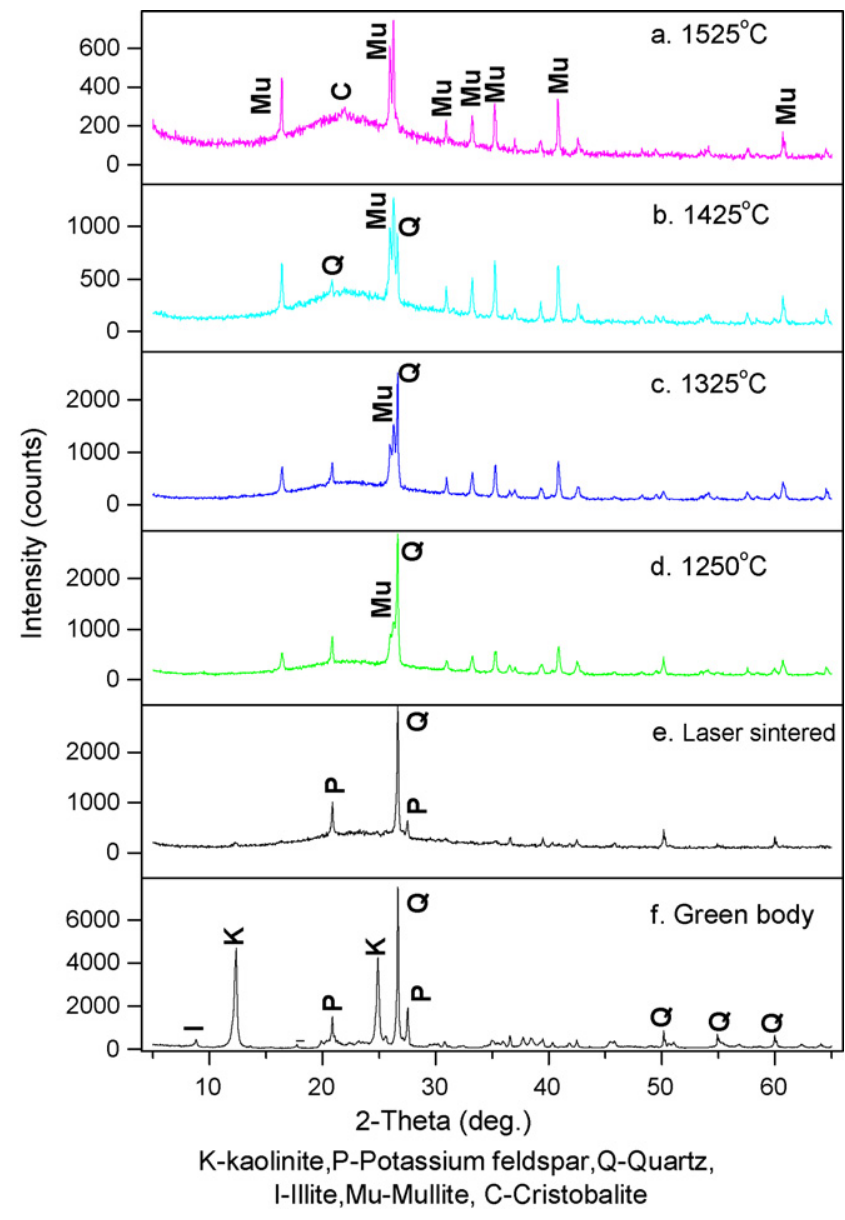

Fig. 19. XRD of the porcelain green, laser sintered and post sintered bodies in the $1250-1525^{\circ} \mathrm{C}$ interval.

process is the quartz solution. No change is observed in the quartz phase after being treated by laser (Fig. 19e). By $1325^{\circ} \mathrm{C}$ most of the quartz grains small than $20 \mu \mathrm{m}^{27}$ are completely dissolved; above $1400{ }^{\circ} \mathrm{C}$ little quartz remains and the porcelain consists almost entirely of mullite and glass. Usually the quartz forms only glass, but for the composition in this paper sintered at $1525^{\circ} \mathrm{C}$ there is a transformation into cristobalite (Fig. 19a). After the melt at about $1140{ }^{\circ} \mathrm{C}$ and reaction with the kaolin at about $1250^{\circ} \mathrm{C}$, feldspar phase disappears in Fig. 19d. The mullite phase was detected at $1250^{\circ} \mathrm{C}$. With further increase of temperature mullite crystals continue to grow. After sintering at temperature above $1400^{\circ} \mathrm{C}$, mullite is present as prismatic crystals up to about $0.01 \mathrm{~mm}$ in length (Fig. 20c).

There are three major theories that have been developed to explain the porcelain strength. ${ }^{17}$ Mullite hypothesis, first proposed by Zoellner, ${ }^{25}$ posits that the strength of a porcelain body as solely dependent on the felt-like interlocking of fine mullite needles. Matrix reinforcement hypothesis ${ }^{26}$ suggests that the difference in thermal expansion coefficients between the matrix and dispersed particles (such as quartz and alumina) or crystalline phases formed during firing (such as mullite and cristobalite) produces strong compressive stress on the glassy phase. Such induced "thermal" compressive stress due to the mismatch of thermal expansion leads to strength reinforcement in the porce- 

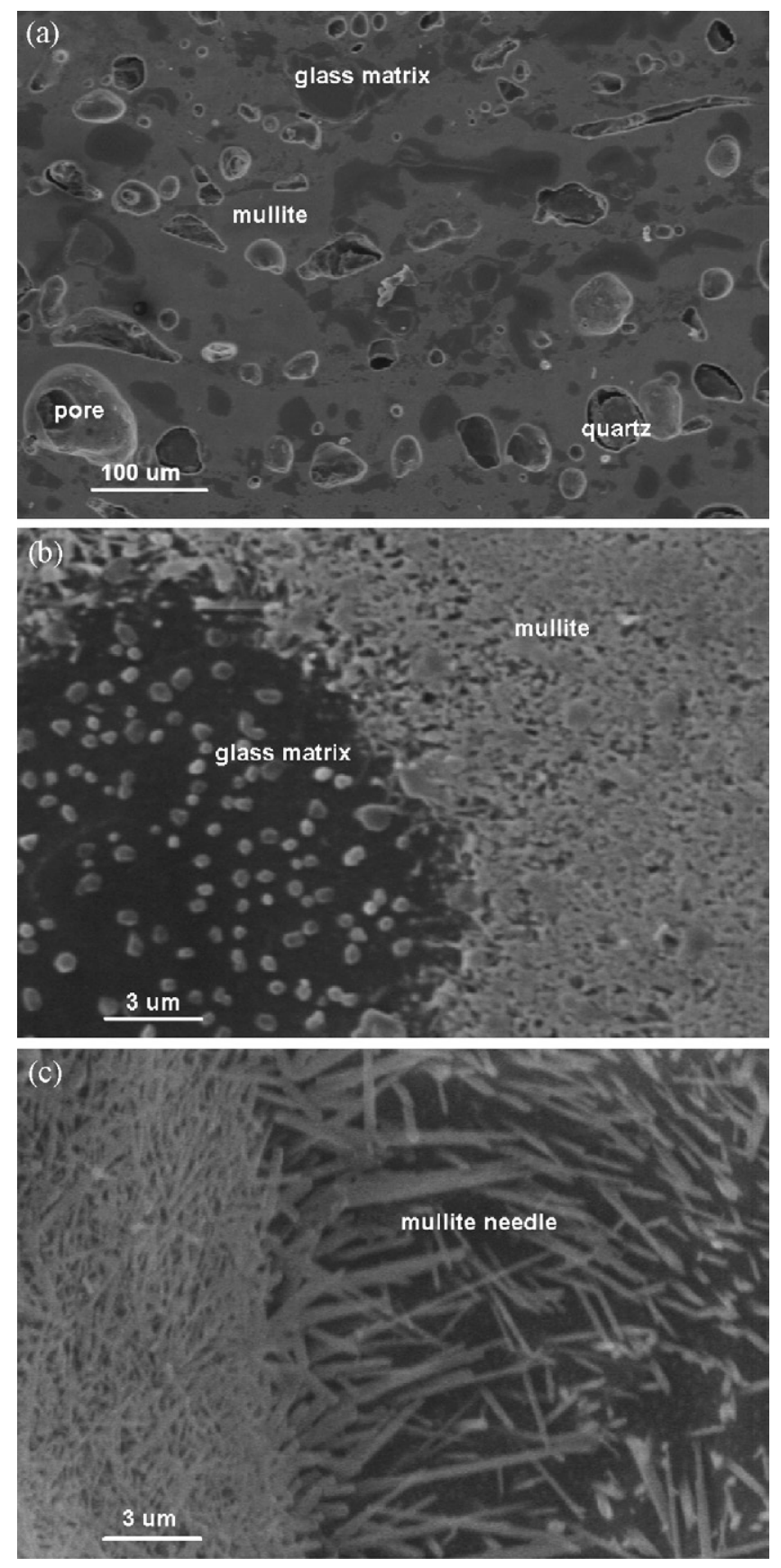

Fig. 20. SEM micrographs of the mullite in the cross-section of a sample sintered at $1475^{\circ} \mathrm{C}$, Sample was polished and then etched using a $10 \% \mathrm{HF}$ solution for $35 \mathrm{~s}$.

lain bodies. The third hypothesis is dispersion-strengthening, which proposes that the dispersed particles limit the size of Griffith flaws, leading to increased strength.

The SEM micrographs of polished and etched cross-section in a sample sintered at $1475^{\circ} \mathrm{C}$ are shown in Fig. 20. Mullite, glass matrix, pores and quartz powders etc. constitute the microstructures of the cross-section. The pores distributed between layers are the major faults and will drastically decrease the mechanical strength of the porcelain bodies. Dense matrix has been observed in one single layer, just between two layers of pores in Fig. 20a, which consists of the mullite and glass phases. The morphological structures of the phases are shown in Figs. 20b and c.

According to Fig. 20, the first two mechanical hypotheses of the porcelain bodies can be used to explain the strength of the samples in the present work. The mullite needles are inlayed into the glass matrix perfectly consistent with the second hypothesis (Fig. 20b). The second mullite in Fig. 20c is interlocked improving the mechanical strength just similar to the first hypothesis. But in the present work, the morphological structures are more similar to the short fiber reinforced resin matrix composite, a typical composite pattern. The mullite needles act like the short fiber and resin is replaced by the glass matrix. The reinforcement mechanism of matrix reinforcement is different with short fiber reinforcement. The former is due to the thermal compressive stress from the thermal expansion mismatch leading to strength improvement. The mechanism of the short fiber reinforcement is that the short fiber could limit the flaws spread and absorb the fracture energy to realize the mechanical strength improvement. If the reinforcement of glass matrix (instead of resin matrix) with mullite crystalline (the short ceramic fiber) is tenable, the mechanical strength of the porcelain bodies would be influenced by the size and the content of the mullite crystalline. According to the SEM micrographs in Fig. 20, this mechanism is true only in certain areas of the microstructures. More experiments should be conducted in the future work to investigate the influence of the mullite crystalline size and distribution on the mechanical strength to validate this new hypothesis.

\subsubsection{TGA/DTA results and suitable post sintering process}

Fig. 21 depicts the TG/DT analysis results for the green (green lines) and laser sintered (red lines) porcelain bodies. For the green body, a broad endothermic band centered at $\sim 580^{\circ} \mathrm{C}$ is due to both kaolinite dehydroxylation reaction and quartz phase transformation. The mass loss associated to this endothermic process is about $5.75 \%$, which is much lager than the mass loss for the laser sintered body, just $0.61 \%$. It means that the dehydroxylation reaction has been almost finished after the laser sintering process. An exothermic peak at $\sim 1022{ }^{\circ} \mathrm{C}$ is attributed to mullite crystallization both for green and laser sintered bodies.

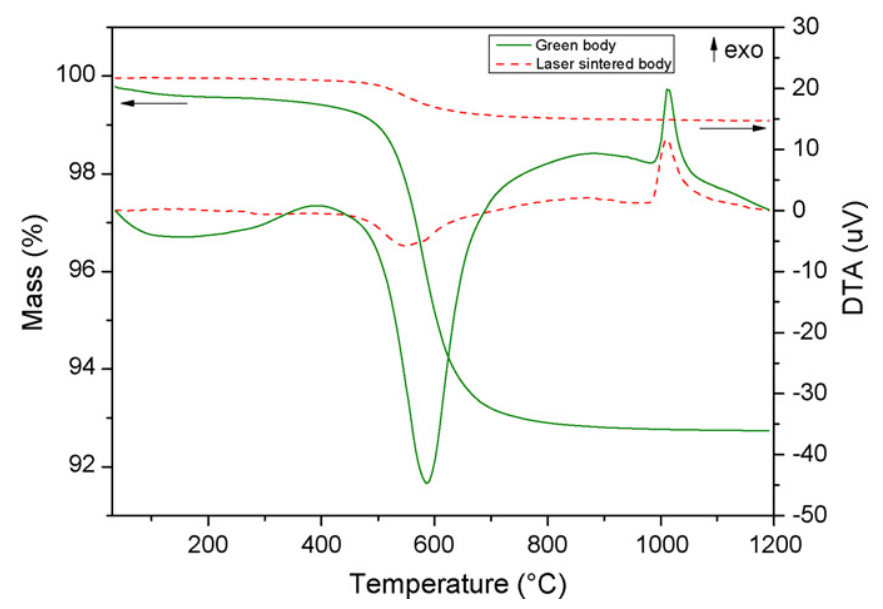

Fig. 21. TGA/DTA curves for porcelain green body and laser sintered body. 


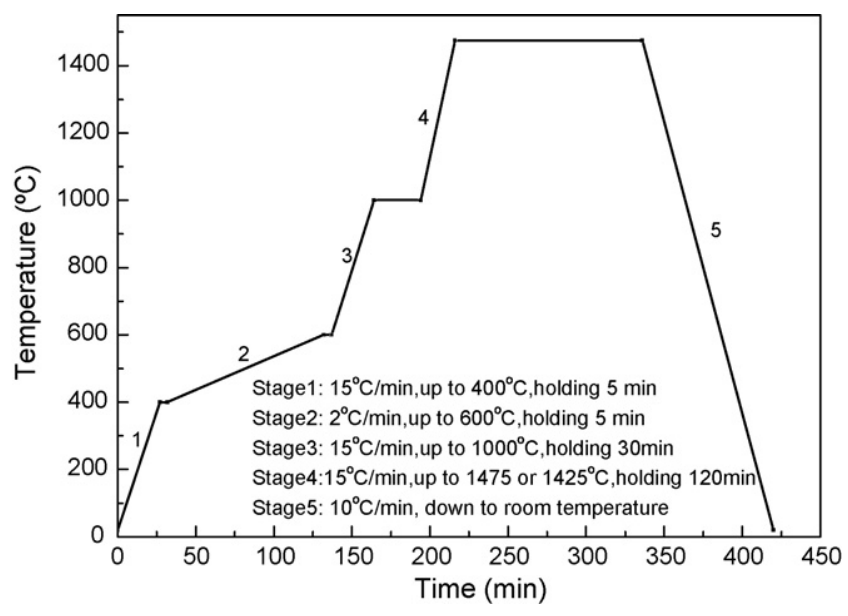

Fig. 22. Suitable post sintering process.

According to all the experiment results, the suitable post sintering process is plotted in Fig. 22. The state of art has been demonstrated by the laser sintered (Fig. 23a) and post sintered (Fig. 23b) porcelain components which were fabricated by the appropriate laser sintering parameters and then post sintered using the process in Fig. 22.
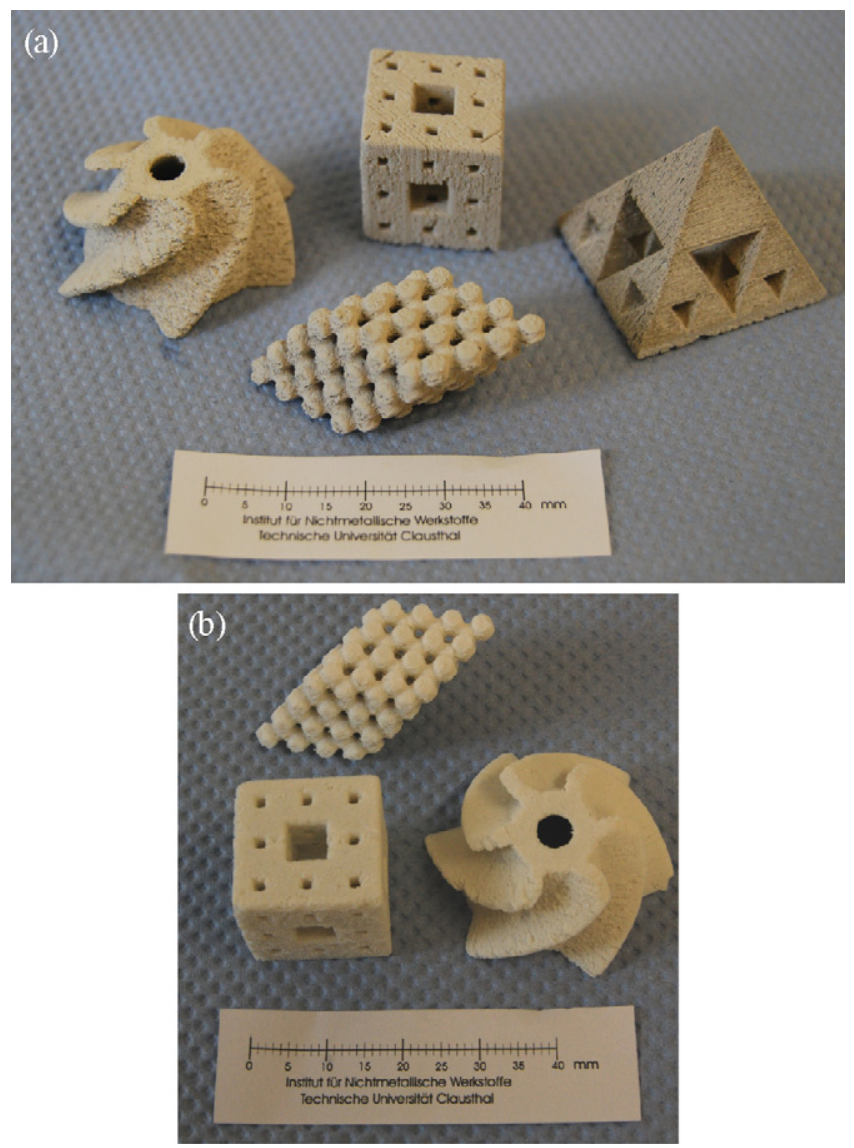

Fig. 23. Demonstration of the state of art, diamond structure, fractal structures and blade wheel; laser sintering parameters: power $50 \mathrm{~W}$, scanning speed $85 \mathrm{~mm} / \mathrm{s}$, and hatching space $0.6 \mathrm{~mm}$. (a) Green bodies after laser sintering and (b) post sintered at $1425^{\circ} \mathrm{C}$.

\section{Conclusion}

Laser energy density and hatching space have different influence on the properties of ceramic bodies. Higher hatching space and lower laser energy density produce higher final mechanical strength. A stress relief principle has been proposed in this paper to explain the influence of laser energy density and hatching space on the microstructure and mechanical properties of ceramic samples.

Heating rate and holding time have an insignificant influence on the properties of the porcelain bodies during the post sintering process. Sintering temperature is the most important factor and has been chosen to the range of $1425-1475^{\circ} \mathrm{C}$ in the present work. Maximum bending strength, $34 \pm 4.9 \mathrm{MPa}$, was achieved using the selected post sintering process.

According to the properties of the ceramic bodies, appropriate laser sintering parameters, power $50 \mathrm{~W}$, scan speed $85 \mathrm{~mm} / \mathrm{s}$ and hatching space $0.6 \mathrm{~mm}$, have been attained in the present work. Some components with complex structures have been fabricated to validate the state of art at the end of this paper.

\section{Acknowledgements}

The authors are deeply indebted to Mr. Görke for the adjustment of the experiment equipments and TGA/DTA/SEM analysis, Mrs. Ohlendorf for machining the samples and $\mathrm{Mr}$. Zellmann for the XRD analysis and density measurement.

\section{References}

1. Padture, N. P., Gell, M. and Jordan, E. H., Thermal barrier coatings for gas-turbine engine applications. Science, 2002, 296, 280-284.

2. Safari, A., Allahverdi, M. and Akdogan, E. K., Solid freeform fabrication of piezoelectric sensors and actuators. J. Mater. Sci., 2006, 41, 177198.

3. Miyamoto, Y., Kirihara, S., Kanehira, S., Takeda, M. W., Honda, K. and Sakoda, K., Smart processing development of photonic crystals and fractals. Int. J. Appl. Ceram. Technol., 2004, 1, 40-48.

4. Chen, W., Kirihara, S. and Miyamoto, Y., Microfabrication of threedimensional photonic crystals of $\mathrm{SiO}_{2}-\mathrm{Al}_{2} \mathrm{O}_{3}$ ceramics and their terahertz wave properties. Int. J. Appl. Ceram. Technol., 2008, 5, 228-233.

5. Regenfuss, P., Streek, A., Ullmann, F., Kühn, C., Hartwig, L., Horn, M., Ebert, R. and Exner, H., Laser micro sintering of ceramic materials. Interceram, 2007, 56, 420-422.

6. Stampfl, J., Liu, H.-C., Nam, S. W., Sakamoto, K., Tsuru, H., Kang, S., Cooper, A. G., Nickel, A. and Prinz, F. B., Rapid prototyping and manufacturing by gelcasting of metallic and ceramic slurries. Mater. Sci. Eng. A, 2002, 334, 187-192.

7. Hinczewski, C., Corbel, S. and Chartier, T., Ceramic suspensions suitable for stereolithography. J. Eur. Ceram. Soc., 1998, 18, 583-590.

8. Friedel, T., Travitzky, N., Niebling, F., Scheffler, M. and Greil, P., Fabrication of polymer derived ceramic parts by selective laser curing. J. Eur. Ceram. Soc., 2005, 25, 193-197.

9. Günster, J., Engler, S. and Heinrich, J. G., Forming of complex shaped ceramic products via layer-wise slurry deposition (LSD). Bull. EcerS, 2003, 1, 25-28.

10. Gahler, A., Heinrich, J. G. and Günster, J., Direct laser sintering of $\mathrm{Al}_{2} \mathrm{O}_{3}-\mathrm{SiO}_{2}$ dental ceramic components by layer-wise slurry deposition. J. Am. Ceram. Soc., 2006, 89, 3076-3080.

11. Wang, J. and Shaw, L. L., Rheological and extrusion behaviour of dental porcelain slurries for rapid prototyping applications. Mater. Sci. Eng. A, 2005, 397, 314-321. 
12. Li, X., Wang, J., Shaw, L. L. and Cameron, T. B., Laser densification of extruded dental porcelain bodies in multi-material laser densification process. Rapid Prototyping J., 2005, 1, 52-58.

13. Stathis, G., Ekonomakou, A., Stournaras, C. J. and Ftikos, C., Effect of firing conditions, filler grain size and quartz content on bending strength and physical properties of sanitary ware porcelain. J. Eur. Ceram. Soc., 2004, 24, 2357-2366.

14. Isik Ece, O. and Nakagawa, Z., Bending strength of porcelains. Ceram. Int., 2002, 28, 131-140.

15. Maity, S. and Sarkar, B. K., Development of high-strength whiteware bodies. J. Eur. Ceram. Soc., 1996, 16, 1083-1088.

16. Carbajal, L., Rubio-Marcos, F., Bengochea, M. A. and Fernandez, J. F., Properties related phase evolution in porcelain ceramics. J. Eur. Ceram. Soc., 2007, 27, 4065-4069.

17. Carty, W. M. and Senapati, U., Porcelain-raw materials, processing, phase evolution, and mechanical behaviour. J. Am. Ceram. Soc., 1998, 81, $3-20$.

18. Dingal, S., Pradhan, T. R., Sarin Sundar, J. K., Roy Choudhury, A. and Roy, S. K., The application of Taguchi's method in the experimental investigation of the laser sintering process. Int. J. Adv. Manuf. Technol., 2007, 10, $1154-1165$
19. Ross, R. J., Taguchi Methods and QFD: Hows and Whys for Management. ASI Press, Dearborn, Michigan, 1988.

20. Cochran, W. G. and Cox, G. M., Experimental Design (2nd edn.). Wiley, New York, 1992.

21. Weiser, M. W. and Fong, K. B., Experimental design for improved ceramic processing, emphasizing the Taguchi method. Am. Ceram. Soc. Bull., 1993, 72, 87-92.

22. Roy, R. K., Design of Experiments Using the Taguchi Approach. John Wiley \& Sons, New York, 2001.

23. Nelson, J. C., Vail, N. K., Barlow, J., Bourell, D. L. and Marcus, H. L., Selective laser sintering of polymer-coated silicon carbide. Ind. Eng. Chem. Res., 1995, 34, 1641-1649.

24. Martin-Marquez, J., Rincon, J. Ma. and Romero, M., Effect of firing temperature on sintering of porcelain stone ware tiles. Ceram. Int., 2007., doi:10.1016/j.ceramint.2007.06.006.

25. Zoellner, A., Some chemical and physical properties of porcelain. Sprechsall, 1908, 41, 471-473.

26. Rado, P., The strange case of hard porcelain. Trans. Br. Ceram. Soc., 1971, 71, 131-139.

27. Kingery, W. D., Introduction to Ceramics. John Wiley \& Sons, Inc., New York \& London, 1960. 